Proceedings

\title{
Solidly Mounted Resonator (SMR) Sensors for Biomedical Applications ${ }^{+}$
}

\author{
Siavash Esfahani *, Jan Peter Specht, George Jolly, Marina Cole and Julian W. Gardner \\ School of Engineering, University of Warwick, Coventry CV4 7AL, UK; J.P.Specht@warwick.ac.uk (J.P.S.); \\ George.Jolly@warwick.ac.uk (G.J.); Marina.Cole@warwick.ac.uk (M.C.); J.W.Gardner@warwick.ac.uk (J.W.G.) \\ * Correspondence: siavash.esfahani@warwick.ac.uk \\ + Presented at the 4th International Conference nanoFIS 2020-Functional Integrated nano Systems, Graz, \\ Austria, 2-4 November 2020.
}

Published: 10 December 2020

\begin{abstract}
Biosensors play a key role in medical diagnostics, and acoustic wave technology such as solidly mounted resonators (SMRs) applied to this field is one of the latest developments with great potential. This study seeks to explore the potential application of SMRs to detect and quantify prostate-specific antigen (PSA) for the screening and diagnosis of prostate cancer. The primary results show promising frequency shift of SMR sensors coated with Polydimethylsiloxane (PDMS) to different liquids. The SMR frequency is $1.082,1.084$ and $1.088 \mathrm{GHz}$, respectively, to air, deionized water and toluene (liquid) presence. These sensors have great potential as an accurate, low-cost method for measuring PSA and biomarkers for cancer and other diseases.
\end{abstract}

Keywords: solidly mounted resonator (SMR); biosensor; medical diagnostics; liquid biosensing

\section{Introduction}

Prostate cancer is the second most prevalent cancer in men worldwide. According to the UK cancer research, in the UK male population, 1 in 6 will be diagnosed by prostate cancer [1]. Annually, there are an estimated 1.6 million new cases of prostate cancer and approximately 666,000 deaths [2]. Prostate-specific antigen (PSA) is a biomarker that, when elevated, indicates a greater risk of prostate cancer. However, there is currently no screening program in place in the United Kingdom to identify patients at risk of prostate cancer [3]. There are several methods of testing the level of PSA in the blood and urine; however, there are limitations to these tests relating to the accuracy, cost and time required for each test. The theory behind using Film Bulk Acoustic Resonator (FBAR) sensors as liquid biosensors was demonstrated over a decade ago by Weber et al. in 2006. They highlight the ability of these acoustic sensors to detect changes in the mass of up to $2.3 \mathrm{ng} / \mathrm{cm}^{2}$ [4].

\section{Materials and Methods}

The system concept uses two SMRs, one with a biological coating to detect PSA, another without as a reference, and uses the difference between the signal to calculate the mass of antigen on the surface of the coated SMR. These sensors have been used primarily for gas sensing in the Microsensors and Bioelectronics Laboratory (MBL), and therefore liquid testing is the first step in adopting this sensor for liquid biosensing. The SMR sensor is mounted on a printed circuit board PCB oscillator board based on a pierce oscillator. PDMS was chosen as a polymer coating due to its ability to detect volatile organic compound (VOC) in a gaseous state [5]. The PDMS solution was prepared by combining uncured PDMS and curing agent in a 10:1 ratio by weight. This preparation was dissolved in hexane to $3.5 \% \mathrm{w} / \mathrm{w}$ using $600 \mu \mathrm{L}$ of PDMS preparation and $30 \mathrm{~mL}$ of hexane. The polymer mixture was solvated at room temperature for $24 \mathrm{~h}$ using a magnetic stirring plate. 


\section{Results}

Initial testing was carried out using a single drop of deionized water and toluene on the sensing area of the single SMR device. The initial frequency of the SMR device after coating with PDMS was $1.082 \mathrm{GHz}$ in the presence of air. This value changed to $1.084 \mathrm{GHz}$ after dropping deionized water on the surface of SMR. In the presence of toluene, the frequency changed to $1.088 \mathrm{GHz}$, see Figure 1.

(a)

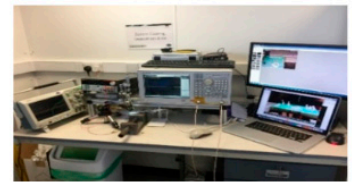

(c)

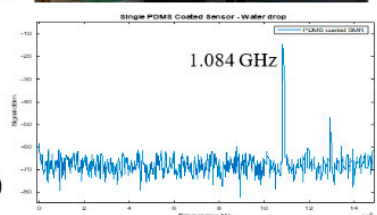

(b)

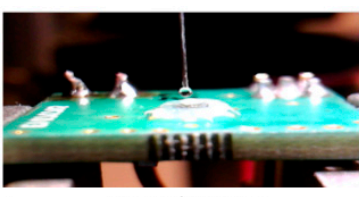

(d)

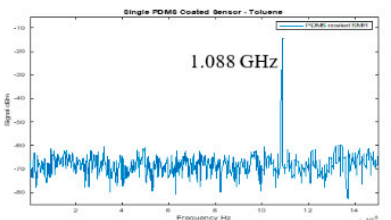

Figure 1. (a) Experimental setup; (b) typical image of dropping liquid on solidly mounted resonator (SMR) device; (c) response of SMR device to water; and (d) response of SMR device to toluene.

\section{Conclusions}

In this paper, we report the possibility of using SMR devices for the liquid phase and the results to indicate that the SMRs with a PDMS coating are capable of detecting changes in liquids from deionized water to toluene. The frequency shift between these two liquids is $4 \mathrm{MHz}$. Further work is required to test the system with reference and sensing SMR with different concentrations of toluene.

Funding: The authors gratefully acknowledge the financial support under the scope of the COMET program within the K2 Center "Integrated Computational Material, Process and Product Engineering (IC-MPPE)" (Project No 859480). This program is supported by the Austrian Federal Ministries for Transport, Innovation and Technology (BMVIT) and for Digital and Economic Affairs (BMDW), represented by the Austrian research funding association (FFG), and the federal states of Styria, Upper Austria and Tyrol.

Conflicts of Interest: The authors declare no conflict of interest.

\section{References}

1. UK, Cancer Research. Prostate Cancer Statistics. Cancer Statistics 2018. Available online: https://www.cancerresearchuk.org/health-professional/cancer-statistics/statistics-by-cancertype/pancreatic-cancer\#heading-Two (accessed on 7 February 2020).

2. Fitzmaurice, C.; Allen, C.; Barber, R.M.; Barregard, L.; Bhutta, Z.A.; Brenner, H.; Dicker, D.J.; ChimedOrchir, O.; Dandona, R.; Dandona, L.; et al. Global, regional, and national cancer incidence, mortality, years of life lost, years lived with disability, and disability-adjusted life-years for 32 cancer groups, 1990 to 2015 : A systematic analysis for the global burden of disease study. JAMA Oncol. 2017, 3, 524-548.

3. NHS. Routine Blood Test for Prostate Cancer 'Doesn't Save Lives'. Behind the Headlines 2018. Available online: https://www.nhs.uk/news/cancer/routine-blood-test-prostate-cancer-doesnt-save-lives/ (accessed on 7 February 2020).

4. Weber, J.; Albers, W.M.; Tuppurainen, J.; Link, M.; Gabl, R.; Wersing, W.; Schreiter, M. Shear mode FBARs as highly sensitive liquid biosensors. Sens. Actuators A: Phys. 2006, 128, 84-88.

5. Villa-López, F.H. CMOS Compatible Solidly Mounted Resonator for Air Quality Monitoring. Ph.D. Thesis, University of Warwick, Coventry, UK, 2017.

Publisher's Note: MDPI stays neutral with regard to jurisdictional claims in published maps and institutional affiliations.

C 2020 by the authors. Licensee MDPI, Basel, Switzerland. This article is an open access article distributed under the terms and conditions of the Creative Commons Attribution (CC BY) license (http://creativecommons.org/licenses/by/4.0/). 